\title{
Formação matemática no curso Normal do Instituto de Educação Régis Pacheco (1959-1971)
}

\author{
Mathematics Education on the Normal course in Education Institute \\ Régis Pacheco (1959-1971)
}

\author{
Cleide Selma Pereira dos Santos ${ }^{1}$ \\ Janice Cassia Lando ${ }^{2}$
}

\section{Resumo}

No presente artigo apresentamos alguns resultados de uma pesquisa de mestrado, na qual buscamos compreender como se constituiu a formação matemática dos normalistas do Curso Normal do Instituto de Educação Régis Pacheco, localizado em Jequié-BA. O recorte temporal da pesquisa compreende o período de 1959 a 1971, que correspondem, respectivamente, ao ano em que o citado curso iniciou suas atividades e a promulgação da Lei no 5.692 de 11 de agosto de 1971, que trouxe mudanças importantes para o Curso Normal. Como aportes teóricos fizemos uso da história cultural; utilizamos os conceitos de apropriação na perspectiva de Chartier e história das disciplinas escolares de acordo com André Chervel. Adotamos a história oral temática, conforme propõe Meihy (1996), para produzir depoimentos com três docentes e cinco discentes do curso. Com base nas fontes, - entrevistas, documentos e livros didáticos - conjecturamos que na formação dos normalistas, o ensino de matemática se consolidou a partir da apropriação e institucionalização de saberes, oriundos das disciplinas de formação geral e de saberes advindos da formação profissional, ou seja, dos saberes a ensinar e saberes para ensinar a matemática, respectivamente.

Palavras chave: Curso Normal do IERP; saberes para ensinar matemática; Instituto de Educação Régis Pacheco.

\section{Abstract}

In the present article we present some results of a masters research, in which we seek to understand how the mathematics formation of the Curso Normal do Instituto de Educação Régis Pacheco located in Jequié - BA was constituted. The temporal cut of the research comprises the period from 1959 to 1971, which correspond, respectively, to the year that the course began the activities and the promulgation of Law No. 5,692 of August 11, 1971, which brought important changes to the Curso Normal. As theoretical contributions we made use of cultural history; we use the concepts of appropriation from Chartier perspective and the history of school subjects, according to André Chervel. We adopted the thematic oral history, as proposed by Meihy (1996), to produce testimonies with three teachers and five

\footnotetext{
${ }^{1}$ Universidade Estadual do Sudoeste da Bahia|cleideselma10@hotmail.com

2 Universidade Estadual do Sudoeste da Bahia | janicelando@gmail.com
} 
students of the course. Based on the sources - interviews, documents and textbooks - we conjecture that in the formation of the normalistas, the mathematics teaching was consolidated from the appropriation and institutionalization of knowledge, coming from the disciplines of general formation and from the knowledge derived from professional training, or teaching knowledge and knowledge to teach mathematics, respectively.

Keywords: Normal course IERP; knowledge to teach Mathematics; Régis Pacheco Institute.

\section{Introdução}

O Instituto Estadual de Educação Régis Pacheco (IERP) atualmente é denominado de Centro Estadual de Educação Profissional em Gestão e Tecnologia da Informação Régis Pacheco (CEEP Régis Pacheco). Desde a sua fundação até o momento presente o colégio recebeu várias denominações, contudo, adotamos o nome IERP, por esse nome ser predominante em maior tempo de sua existência, além disso, a instituição ainda é conhecida pela maioria da população por essa designação.

A Escola Normal do IERP foi fundada em 1959, como anexo do Ginásio Estadual de Jequié. O Ginásio Estadual de Jequié, posteriormente denominado Instituto de Educação Régis Pacheco, foi proposto pela lei no 130 de 14 de dezembro de 1948 (BAHIA, 1948), contudo, só foi inaugurado em 1952, devido a questões políticas que se constituíram como empecilhos no processo de implementação desse projeto. Junto ao Ginásio Estadual de Jequié, havia a promessa da implantação de uma Escola Normal, contudo, embora a lei no 737/55 (BAHIA, 1955) declarasse que no ano seguinte deveria funcionar uma Escola Normal, anexa ao ginásio público, a mesma só veio a ser implantada em 1958, em consonância ao que propôs o decreto no 17. 234 de 14 de dezembro de 1958, que criou o Curso Pedagógico, anexo ao Colégio Estadual de Jequié e deu outras providências. Entre os fatores que dificultaram a instalação de ambos os cursos, as fontes nos permitiram interpretar que os interesses distintos entre os que defendiam a escola pública e os que defendiam a escola particular em Jequié se constituíram como sendo os fatores basilares de tal morosidade.

Por entendermos que as Escolas Normais contribuíram significativamente para o processo de profissionalização docente e a importância do conhecimento histórico para a contemporaneidade, buscamos realizar uma investigação histórica no intuito de compreender como ocorreu a formação matemática dos estudantes do Curso Normal do Instituto de Educação Régis Pacheco (IERP), em Jequié, no período de 1959 a 1971. Esse recorte temporal justifica-se pelo fato de o Curso Normal do IERP ter sido implantado em 1959 e pelo mesmo ter passado por alterações significativas a partir da Lei no 5.692 de 11 de agosto de 1971, mudando, inclusive, sua nomenclatura (TANURI, 2000). Neste artigo, especificamente, pretendemos responder a questão: que saberes estavam presentes na formação matemática dos normalistas da instituição pesquisada?

A pesquisa foi realizada na perspectiva da história cultural que de acordo com Chartier (2002, p. 16-17) "tem por principal objetivo identificar o modo como em diferentes lugares e momentos uma determinada realidade é construída, pensada e dada a ler". Se fundamentou também na concepção de disciplina escolar segundo Chervel (1990), o qual afirma que a história das disciplinas é produto da construção histórica do ensino em épocas e contextos diferentes, pois a organização interna das mesmas é realizada a partir dos consensos abstraídos de discussões em torno dos métodos e conteúdos adotados. Diante 
disso, o autor destaca que o estudo das disciplinas escolares deve despender um esforço em interpretar tanto a história de seus conteúdos e métodos utilizados, bem como, as finalidades a que se propunha e os resultados que produziram.

Utilizamos a história oral temática numa perspectiva histórica, a qual "é quase sempre usada como técnica, pois articula, na maioria das vezes, diálogos com outros documentos" (MEIHY, 1996, p. 67). Assim, a história oral se caracteriza como um recurso utilizado para a elaboração de documentos, nesse sentido, utiliza-se de entrevistas como se fosse mais um documento (MEIHY, 1996). Ressaltamos que as entrevistas foram realizadas com professores e alunos que, respectivamente, lecionaram e estudaram no Curso Normal do IERP, no período de 1959 a 1971. O roteiro de perguntas que norteou a entrevista teve como objetivo conhecer a formação dos professores, os conteúdos abordados no ensino da matemática no Curso Normal do IERP, as orientações teóricas e metodológicas abordadas no curso, no período em estudo, entre outros.

Além dos depoimentos, utilizamos outros documentos como fontes históricas, entre os quais estão: pastas de estudantes concluintes, legislação educacional, artigos de revistas, edital de concursos, entre outros que tratam do ensino da matemática e da formação de professores no Curso Normal do IERP. Utilizamos também livros didáticos, os quais foram identificados por uma das discentes, como tendo sido utilizado pelos estudantes do citado curso.

Com base nas fontes, elaboramos uma narrativa, entre outras possíveis, no intuito de apresentar nossa compreensão sobre os saberes presentes na formação matemática dos discentes do Curso Normal do IERP, já que esse foi o objetivo proposto para este artigo. Nesse sentido, este texto está organizado em dois tópicos, são eles: Rememorando os saberes a ensinar: o que ensinar articulado ao como ensinar no primário e; Saberes para ensinar matemática: algumas considerações. Em seguida, trazemos algumas considerações sobre a discussão realizada ao longo do trabalho.

A organização da escrita de nosso texto se fundamenta na discussão realizada por Rita Hofstetter e Bernard Schneuwly (2017a), que com base em análises realizadas pela Equipe de Pesquisa em História das Ciências da Educação (ERHISE), da Universidade de Genebra, na Suíça, sobre a organização dos saberes profissionais institucionalizados para a profissão docente, afirmam que têm revelado que as Escolas Normais oferecem uma formação tanto geral como profissional. Ainda, segundo esses autores, os saberes a ensinar eram enfoque da formação geral, a qual se refere a um conjunto de disciplinas ministradas em nível secundário, provenientes dos campos disciplinares de referência, produzidos pelas disciplinas universitárias e os saberes para ensinar se referem aos saberes constitutivos do campo profissional, emanados das ciências da educação, responsáveis pela expertise profissional, ou seja, por uma formação específica para o ensino, capaz de tornar os docentes conhecedores de seu ofício para atuarem com perfeição.

\section{Rememorando os saberes a ensinar: o que ensinar articulado ao como ensinar no primário}

A partir de uma análise da grade curricular do Curso Normal do IERP percebemos que as disciplinas destinadas às orientações para o ensino sobressaíam no currículo com relação às disciplinas que abordavam conteúdos específicos de matemática, o que nos remete a 
Bertini, Morais e Valente (2017) quando afirmam que com a crescente preocupação com relação à formação de professores, foram surgindo rubricas específicas no currículo dos cursos destinados à formação docente.

Por outro lado, no IERP, ressaltamos que os conteúdos específicos de matemática não se faziam presentes apenas nas disciplinas de Matemática, Desenho e Estatística, já que de acordo com algumas depoentes, as disciplinas que eram destinadas a orientar as formas de ensino - Didática, Didática da Matemática, Didática da Língua e Matemática - também abordavam sobre os conteúdos específicos de matemática, orientando como ensiná-los.

O depoimento de Niza Guimarães Pereira (2017) - discente do Curso Normal do IERP no período de 1963 a 1965 - esclarece que "[...] no normal não era o forte a matemática, o forte era a parte de didática, de aprender a dar aula, a matemática era como o português, o importante era saber quais os conteúdos que você iria trabalhar com as crianças". Desse modo, consideramos viável supor que a formação do normalista se dava numa perspectiva de aprender como ensinar, dando ênfase a conhecimentos teóricos e metodológicos, os saberes para ensinar, os quais davam aos normalistas a expertise profissional, ou seja, caracterizavam a profissão professor. Contudo, os conhecimentos específicos da disciplina também se faziam presente, mas com menor ênfase.

No quadro de disciplinas do Curso Normal do IERP, havia uma disciplina denominada Matemática. Essa disciplina, durante algum tempo, tratava de conteúdos matemáticos abordados em outros cursos do nível secundário, é o que afirma Niza Guimarães Pereira (2017) ao relatar sobre sua experiência com o ensino da matemática no Curso Normal do IERP, "comecei a perceber que a matemática que davam para gente não tinha nada a ver, como eu comecei a fazer o científico e o normal ao mesmo tempo, percebi que a matemática do Curso Normal estava igual com a do científico".

A esse respeito, Rosas $(1959)^{3}$ destaca que ao analisar tanto as legislações como as peculiaridades locais dos diversos cursos de formação de professores primários do Brasil, na década de 1950, não encontrou legislação específica sobre a matemática a não ser a introdução da disciplina no currículo, constatou uma variação nos programas dos estados e que as instruções metodológicas propostas para o ensino da matemática no Curso Secundário, por intermédio da portaria no 1.045 de 14 de dezembro de 1951, puderam ser adotadas pelos cursos de formação de professores primários, já que o ensino normal compreendia também o nível secundário, de grau médio.

Se por um lado, Niza Guimarães Pereira (2017) compara o ensino de matemática do Curso Normal com o do Científico. Por outro lado, Anísia Rosa Tourinho Simões de Carvalho (2016), docente do IERP no período de 1956 a 1986, aproximadamente, faz um comparativo entre o ensino da matemática no Curso Normal e no ginásio. Para Anísia Rosa Tourinho Simões de Carvalho (2016), o ensino de matemática no Curso Normal do IERP era "a mesma coisa do Ginásio, aqueles mesmos conteúdos".

Diante do exposto, consideramos importante ressaltar que Niza Guimarães Pereira (2017) falou enquanto estudante do Curso Normal no período de 1963 a 1965, Anísia Rosa Tourinho Simões de Carvalho (2016) foi docente de desenho no Curso Normal e no Ginásio do IERP, ou seja, as visões das depoentes são diferenciadas, falam, a partir de um olhar particular, de perspectivas distintas sobre o curso. Nesse sentido, Chartier (2002) ressalta

\footnotetext{
${ }^{3}$ Texto publicado nos anais do III Congresso Brasileiro do Ensino da Matemática, realizado em 1959.
} 
que a realidade é apreendida pelos sujeitos de forma diferenciada, os quais têm uma forma própria de estarem no mundo e, assim, se apropriam de discursos e representações em um contexto de disputas e concorrências.

Com relação à semelhança entre os conteúdos abordados no Curso Normal com os do Ginásio, a professora Anísia Rosa Tourinho Simões de Carvalho (2016) afirma que:

Naquela época o professor não era especializado para ensinar a matemática no magistério, era professor de ginásio que pegaram e colocaram para ensinar matemática, tanto no curso normal do IERP como no Curso Normal do Ginásio do Padre, os professores não tinham assim, aquela formação do ensino da matemática.

Isso pode ser explicado se considerarmos o que afirma Búrigo (2013), quando relata que no contexto de expansão acelerada do ensino primário e médio, na década de 1960, o ensino de matemática encontrou alguns desafios, entre os quais se destacou a falta de capacitação dos docentes para o ensino da referida disciplina.

A comparação de conteúdos realizada pela aluna, Niza Guimarães Pereira (2017), nos remete ao que destaca Valente (2011) quando este afirma que os cursos de formação do professor primário são herdeiros da cultura escolar do ensino secundário, em decorrência do fato das Escolas Normais serem instituídas como um anexo dos Liceus, acrescentando ao currículo destes apenas uma cadeira de pedagogia, assim, transportava-se a matemática do $1^{\circ}$ ano do secundário para o Curso Normal. Desse modo, é relevante salientar que a Escola Normal de Jequié surgiu como um anexo do Ginásio Estadual de Jequié.

Diante disso, conjecturamos que esse contexto contribuiu para que a Escola Normal do IERP também aderisse à cultura escolar do Ginásio Estadual de Jequié. Destacamos que o Curso Científico foi implantado pouco tempo antes da fundação do Curso Normal (ARAÚjO, 2012). Dessa forma, por considerar que o Curso Normal ocorria após o ginásio assim como o Curso Científico e que havia propostas de mudanças para o ensino da matemática no ensino secundário naquele período, pressupomos que os docentes da disciplina específica de matemática podem ter pensado que deveriam ministrar os mesmos conteúdos do científico no Curso Normal, conforme pontuamos o que constatou Rosas (1959) numa pesquisa sobre outros Cursos Normais.

A partir de uma análise sobre os conteúdos estabelecidos pela portaria n 1.045 de 14 de dezembro de 1951 e com base nos depoimentos produzidos em nossa pesquisa, conjecturamos que o Curso Normal do IERP, durante maior parte de sua vigência, adotou em seu programa os conteúdos destinados à primeira série ginasial, explícitos nessa portaria, já que estes são citados pelas depoentes e também são abordados no primário, nível de ensino em que os normalistas atuavam.

Constatamos que alguns dos conteúdos expressos na portaria nº 1.045 de 1951 são abordados pelo livro O ensino da aritmética pela compreensão, publicado em 1965, que compõe a coleção Didática da matemática na escola primária, destinada a orientar o ensino de matemática aos futuros professores. Importa destacar que esse livro foi identificado por Dilma Santana Miranda (2017) - discente do Curso Normal do IERP no período de 1965 a 1967 - como um dos livros que compôs a citada coleção, a qual foi utilizada pelas normalistas do IERP.

O livro O ensino da aritmética pela compreensão, apresenta orientações para o ensino dos seguintes conteúdos de aritmética: divisão de números inteiros, multiplicação e adição de frações, adição e subtração de frações, conceitos sobre frações ordinárias, frações 
decimais, identificação das partes de uma fração, comparação entre frações, significação de numerador e denominador, simplificação de frações aos menores termos, frações próprias e impróprias, números mistos, adição de frações com denominadores iguais e diferentes, mínimo múltiplo comum (MMC), operações de adição, subtração, multiplicação e divisão de frações ordinárias e decimais por número inteiro ou pelo mesmo tipo de fração, multiplicação de número misto e número inteiro, divisão de número inteiro por fração e vice-versa, divisão de números mistos, relações entre frações ordinárias, decimais e porcentagem; multiplicação por 10 ou potência de 10; divisão entre números decimais; divisão de números decimais por números inteiros e vice-versa; pensamento quantitativo e resolução de problemas, desenvolvimento de conceitos matemáticos básicos para a resolução de problemas, porcentagem, desenvolvimento de leitura e vocabulário aritmético, sistema de medidas, operações com medidas, cálculo de figuras geométricas.

Além dos citados conteúdos, esse livro traz uma abordagem sobre avaliação em aritmética e sobre diagnóstico e orientação corretiva em aritmética, ou seja, também aborda a respeito dos saberes para ensinar. Percebemos nesse livro a presença marcante do ensino de frações o que nos remete ao depoimento da discente, Nina Rosa Braga Cardoso (2017) quando afirma que estudava tudo sobre fração. Importa destacar que o citado livro começa com o capítulo 9 e afirma que no anterior, houve uma abordagem a respeito da relação entre divisão, multiplicação, subtração e adição, o que nos leva a acreditar que o mesmo também discutiu formas de ensinar as quatro operações e não somente a divisão.

Os depoimentos revelam uma relação entre conteúdos abordados no nível primário com os que eram ensinados no Curso Normal. A esse respeito, Dilma Santana Miranda (2017), formada em 1967, ao rememorar os conteúdos de matemática estudados no Curso Normal do IERP relata que estudou:

Tudo da matemática, eu me lembro bem, fração, fatoração, numeração, números pares, números ímpares, algarismos romanos, numerais, números ordinais, que até hoje eu sei todos, tudo que aprendi naquela época, as quatro operaç̃̃es - adição com todos os seus termos e resultados, subtração, multiplicação, divisão - problemas, expressões numéricas, máximo divisor comum, mínimo múltiplo comum. Tudo isso aprendemos lá e trouxemos para as nossas atividades de docência, porque lá nós aprendemos e na profissão fomos aperfeiçoando.

Desse modo, percebemos que a formação matemática no Curso Normal do IERP dava ênfase a conteúdos de aritmética, considerando o que os normalistas iriam ensinar no curso primário. Contudo, conforme vimos no depoimento de Niza Guimarães Pereira, nem sempre o ensino de matemática do Curso Normal do IERP priorizou os conteúdos que seriam ensinados no primário.

Magnólia Santana de Farias (2017), normalista formada em 1962, ao relatar sobre os conteúdos de matemática abordados no Curso Normal do IERP afirma que o mesmo tratava de:

[...]todo o conteúdo que a gente ia ensinar depois no primário, as operações fundamentais (somar, diminuir, multiplicar e dividir), escrever números, ler números, máximo divisor comum, mínimo múltiplo comum, fração, frações ordinárias, frações decimais e sistema métrico.

A fala de Magnólia ratifica o que foi mencionado por Dilma Santana Miranda (2017), é importante frisar que a primeira concluiu o curso em 1962 e a segunda em 1967. É 
pertinente destacar também que Dilma Santana Miranda e Magnólia Santana de Farias são de um período posterior e anterior, respectivamente, ao período em que Niza Guimarães Pereira cursou o normal, o que nos leva a pensar que as mudanças ocorridas no currículo do Curso Normal do IERP, tanto em termos de disciplinas, como em termos de conteúdos, eram constantes, conforme pudemos perceber ao analisar a grade curricular do curso ao longo do período em estudo.

De acordo com Nina Rosa Braga Cardoso (2017), normalista do IERP no período de 1970 a 1972, ao recordar os conteúdos de matemática abordados durante sua formação, relata que:

Era tudo baseado no que iria se ensinar no primário, eu lembro até que o programa chegava na quarta série primária, chegava até o assunto de fração. [...] Eram os assuntos que a gente ia ensinar: as quatro operações, expressões numéricas, eram regras de divisibilidade, que são regras que ensinam a descobrir quais os números divisores de outros números. Era isso, a gente aprendia o que ia facilitar a vida da gente. Problemas, principalmente problemas, números primos através do crivo de Eratóstenes, tudo que ia ensinar no primário.

Com base no exposto, conjecturamos que a principal intencionalidade do curso consistia em habilitar os futuros professores a dominarem os conteúdos que iriam ministrar no ensino primário. A esse respeito, a discente Jacy Andrade Sturken (2017), normalista do IERP no período de 1969 a 1971, informa que, em sua época, o primeiro ano do curso era reservado para uma revisão dos conteúdos matemáticos, sem uma relação com a didática, vejamos:

Olha, no Curso Normal, o primeiro ano de Magistério a gente estudou matemática mesmo, não foi nada de didática, [...] foi uma revisão de matemática.

Essa revisão só não teve geometria, era uma revisão da matemática... Agora, já no segundo e terceiro ano não era metodologia, era didática, no segundo ano e terceiro ano era didática da matemática e na terceira unidade o estágio, se fazia o estágio.

Diante do excerto, percebemos indícios de uma preponderância do ensino da aritmética e pouca ênfase no ensino de geometria. Percebemos também que o ensino da matemática no Curso Normal do IERP, em maior parte do período em estudo, vislumbrava familiarizar os normalistas com os conteúdos abordados no curso primário, indicando os processos e formas de ensiná-los e revisar os conteúdos ensinados em anos anteriores ao ingresso no citado curso.

\section{Saberes para ensinar matemática: algumas considerações}

Nina Rosa Braga Cardoso (2017), ao descrever como se dava o ensino da matemática durante sua formação no Curso Normal do IERP, afirma que "estudávamos conjunto aprendendo como ensinar". Sendo assim, observamos que havia uma preocupação no citado curso em oferecer aos futuros professores, os conteúdos de matemática e as formas de ensiná-los. Emerson Pinto de Araújo (2017) - diretor e professor de história do IERP, 
atuou nesse instituto no período de 1952 a 1977, aproximadamente - ao relatar sobre como acontecia o ensino da matemática no Curso Normal, relata que:

Era um ensino mais voltado para metodologia...

Era, a preocupação era com o conteúdo, aqueles professores mais modernos que se preocupavam mais com a metodologia, mas aqueles primeiros se preocupavam mais com o conteúdo; a parte de aritmética, as quatro operações. Já se pressupunha que a aluna do Curso Normal já tinha aprendido tudo isso no primário, agora iria aprender como ensinar;

Diante do excerto, conforme mencionado anteriormente, percebemos que no Curso Normal do IERP o ensino da matemática pode ter se desenvolvido de duas formas diferentes, num momento se priorizava somente os saberes a ensinar e em outro momento, que julgamos, com base nas fontes, o mais longo período, os conteúdos específicos eram abordados de forma articulada aos saberes para ensinar. Essa preocupação estava em acordo com o que exigia o mercado de trabalho, pois um edital de recrutação de docentes primários, publicado em 1959, no Diário Oficial do Município de Jequié, além de avaliar os conteúdos específicos de matemática, buscava avaliar o conhecimento didático do professor, dando-se destaque a saberes relacionados ao planejamento, processo de motivação dos alunos, recursos didáticos e formas de avaliação.

Rui Barbosa (1947, p. 135) ao abordar sobre a Escola Normal do Brasil, afirma que a finalidade deste estabelecimento consistiu em "ensinar a ensinar, educar no método de educar", ou seja, seu principal objetivo era habilitar o normalista para a prática real da educação na escola primária, e assim, segundo o autor, fazia-se necessário que o programa da Escola Normal fosse modelado pela escola primária.

A Lei Orgânica do Curso Normal - Lei no 8.530 de 02 de janeiro de 1946 (ESTADOS UNIDOS DO BRASIL, 1946) - apresentava o desenvolvimento e propagação dos conhecimentos e técnicas relativas à educação da infância como uma de suas finalidades. A referida lei ainda destacava que no processo de execução dos programas do Curso Normal atender-se-ia, entre outros, os seguintes pontos:

c) nas aulas de metodologia deverá ser feita a explicação sistemática dos programas de ensino primário, seus objetivos, articulação da matéria, indicação dos processos e formas de ensino, e ainda a revisão do conteúdo desses programas, quando necessário [...]

Desse modo, fica ainda mais perceptível a intencionalidade de articular os saberes a ensinar aos saberes para ensinar no Curso Normal do IERP. Vale evidenciar que além das disciplinas de conteúdos de matemática, havia também no currículo prescrito desse curso, disciplinas voltadas para a orientação sobre como o professor deveria ensinar, entre as quais, destacamos a Psicologia e as Didáticas, que ganharam destaque no contexto da Escola Nova. Segundo os depoimentos, os saberes para ensinar eram também abordados durante os estágios, por intermédio da observação da prática das professoras regentes. Nesse sentido, Niza Guimarães Pereira (2017) destaca que "a orientação era que a gente observasse o estágio, que a gente aprendesse com os professores". Sendo assim, o momento de estágio se consolidava também como um espaço para a aprendizagem de saberes para ensinar e mostra mais uma vez a estreita relação entre a formação docente no 
Curso Normal para o ensino de matemática e o que era proposto e vivenciado nas escolas primárias.

Entre os saberes para ensinar, abordados no Curso Normal do IERP, percebemos uma preocupação com a adoção de práticas motivacionais, no intuito de estimular os estudantes para o processo de ensino e aprendizagem. Segundo as discentes, Nina Rosa Braga Cardoso (2017), Dilma Santana Miranda (2017) e Magnólia Santana de Farias (2017), orientações voltadas para o processo de motivação, o papel da afetividade, os recursos a serem utilizados no ensino, eram realizadas nas disciplinas de Metodologia ou Didática ${ }^{4}$.

Com relação a essas disciplinas, percebemos nos depoimentos das discentes do Curso Normal do IERP, que discussões a respeito do papel do docente no processo motivacional dos estudantes eram realizadas na formação das normalistas do IERP. Nesse sentido, Magnólia Santana de Farias (2017), concluinte do Curso Normal do IERP em 1962 - ao ser indagada se durante sua formação no Curso Normal presenciou discussões com relação à motivação e afetividade - afirma que essas abordagens eram realizadas em Didática. "Em Didática que a gente via tudo isso, como motivar, como arrumar a sala". Desse modo, conjecturamos que o citado curso também se preocupava em discutir aspectos relacionados ao processo motivacional para o ensino e aprendizagem.

De acordo com Hofstetter e Schneuwly (2017 b), desde a virada do século XIX para o século XX, as investigações a respeito da criança, sua educação e seu desenvolvimento conquistaram certa legitimidade científica. Embora as ciências da educação englobem um conjunto de disciplinas, constatamos maiores indícios de pressupostos teóricos e metodológicos, oriundos das disciplinas Psicologia, Metodologia e Didática, que estiveram presentes na formação das normalistas do IERP.

Na década de 1960, George J. Mouly (1966) ${ }^{5}$ aponta a motivação, a afetividade e o papel do professor como elementos de fundamental importância no processo de ensino e aprendizagem e apresenta o docente como responsável principal no processo motivacional dos estudantes. Sendo assim, esse profissional deveria ter conhecimento na área de psicologia e didática, já que aquela ensinaria ao professor compreender o desenvolvimento da criança e esta ensinaria como ensiná-la, considerando a fase de seu desenvolvimento. A esse respeito, a discente Nina Rosa Braga Cardoso (2017) afirma que na disciplina de psicologia:

O que mais se estudava era a psicologia da criança, para entender as atitudes da criança. A gente tinha que compreender o porquê que a criança era de determinado jeito ou deixava de ser.

[...] Eu lembro bem que ensinava sobre o ego do aluno para entender as atitudes, o desenvolvimento da criança.

Os conhecimentos mencionados pela discente são necessários para a organização do ambiente e processo de motivação dos estudantes para a aprendizagem dos conteúdos das disciplinas, entre elas a matemática, pois percebia-se a necessidade de conhecer os fatores intervenientes no comportamento das crianças que, por sua vez, condicionam a aprendizagem das mesmas para saber como motivá-las e desenvolver um ensino eficiente,

\footnotetext{
${ }^{4}$ A rubrica Metodologia foi utilizada no período de 1959 a 1962, posteriormente, foi substituída pela Didática.

${ }^{5}$ Autor do livro intitulado Psicologia educacional, o qual foi encontrado na biblioteca do IERP.
} 
já que o bom ensino depende também da relação estabelecida entre professor e alunos. Além disso, o conhecimento a respeito das crianças é fundamental para a elaboração dos programas de ensino, ajuda a promover o ajustamento social das crianças e apresentam relevância para o processo de avaliação das mesmas em um contexto onde o aluno é considerado um ser ativo e o professor o promotor do desenvolvimento do processo de ensino e aprendizagem (ADAMS; DICKEY, 1965) ${ }^{6}$.

Georg J. Mouly (1966) afirma que é de responsabilidade do professor proporcionar orientação satisfatória à aprendizagem das crianças sendo que sua tarefa consiste, principalmente, em auxiliar o aprendiz a desenvolver a compreensão da natureza do produto a ser obtido, assim como o processo para atingi-lo; prever e impedir o uso de técnicas erradas, realizando diagnóstico contínuo e auxílio corretivo a fim de evitar a fixação de maus hábitos e; oferecer ao aluno apoio moral e sentimento de segurança e confiança, desse modo, não deve fazer crítica negativa, sobretudo, nos estágios iniciais da aprendizagem. Nessa perspectiva, Jaci Andrade Sturken (2017) destaca em seu depoimento a importância do apoio do docente para a motivação do estudante ao relatar sua experiência no estágio:

Então a professora, ela me chamou particularmente e me falou: têm uns alunos, fulano, fulano e fulano, esses meninos, eles me dão um pouquinho de trabalho. O que foi que eu fiz? Todos os dias, eu falava assim:

_ Até terminar o meu estágio, todo dia um aluno vai tomar conta da sala, da disciplina, de quem estiver conversando, quem não estiver prestando atenção na aula vai anotar, mas vamos começar primeiro por... Eu vou escolher!

Escolhi o considerado pior aluno da sala, o que a professora tinha feito a referência. Pronto! Acabou o problema, isso eu passei até para minhas alunas, porque você tem que valorizar, precisa melhorar a autoestima do aluno, porque você não pode dar reforço negativo. [...]

A gente não pode jogar reforço negativo para cima dos alunos.

"Vocês não querem nada, vocês não sabem nada, eu já fiz minha vida nem quero saber".

Não é assim, na sala de aula você tem que levantar a autoestima do aluno, se você não tiver esse objetivo, não serve para ser professor (grifo nosso).

Com base no excerto, conjecturamos que os saberes voltados para a motivação do estudante, a importância da afetividade e o papel do professor no processo de ensino e aprendizagem da matemática, entre outras questões, foram abordados na formação da citada depoente, já que a fala da mesma nos conduz a pressupor que ao professor dava-se também a incumbência de motivar o aluno para aprendizagem.

Discussões nessa perspectiva estiveram presentes também no II Congresso de Ensino de Matemática de 1957, por exemplo, temos a abordagem de Odila Barros Xavier (1957)

\footnotetext{
6 De acordo com a discente Dilma Santana Miranda, esse livro foi usado pelas normalistas na Biblioteca Municipal de Jequié e comprado pela citada discente, para o seu uso particular e de suas irmãs, que também fizeram o Curso Normal no IERP.
} 
que ratifica a importância dos conhecimentos da área da psicologia para a educação, quando a mesma afirma que a organização de um programa de ensino de matemática implica, entre outros fatores:

[...] uma sadia compreensão da criança: a) de como ela aprende; b) dos tipos ou graus de aprendizagem que esperamos dela; c) de como se desenvolve seu pensamento matemático; d) de como funciona a matemática em sua vida; e) de suas necessidades no campo da matemática - presentes e futuras; f) de como a Matemática se relaciona com o desenvolvimento de sua personalidade.

Desse modo, Xavier (1957) demonstra que havia uma preocupação com a forma como a criança aprendia, com o seu desenvolvimento cognitivo, com a relação dos conteúdos abordados com a vida do aluno e sua personalidade, o que implica numa interação com abordagens que possibilitam o conhecimento a respeito do desenvolvimento infantil, da motivação, da afetividade, dos recursos utilizados no processo de ensino e aprendizagem, entre outros fatores. Conjecturamos que a Didática também tratava de aspectos relacionados ao processo de ensino e aprendizagem e que a motivação, de acordo com o pensamento da época, não envolvia apenas a interação dos indivíduos, mas também o ambiente em que os mesmos se encontravam e os recursos utilizados no processo de ensino e aprendizagem.

De acordo com Chervel (1990, p. 205) a motivação "trata-se não somente de preparar o aluno para a nova disciplina mas de selecionar, aliás com igual peso, os conteúdos, os textos, as narrações mais estimulantes, na verdade de levar-lhe a se engajar espontaneamente nos exercícios". Desse modo, é válido inferir que os métodos se utilizam também dos materiais didáticos para se concretizarem, se constituem em instrumentos utilizados para a motivação dos estudantes e também auxiliam no processo de ensino e aprendizagem, promovem dinamicidade, economia do tempo, enriquecimento à experiência sensorial e estímulo à imaginação (MORAES, 1959). Sendo assim, são selecionados considerando a concepção pedagógica que os atores do processo educativo abraçam, bem como as finalidades do ensino.

De acordo com os depoentes desta pesquisa, para o ensino de matemática no Curso Normal do IERP, o docente utilizava basicamente o quadro negro e o giz, as aulas eram, em sua maioria, expositivas. Essa era uma prática comum em outras instituições de ensino da época. De acordo com Magnólia Santana de Farias (2017), concluinte em 1962, nos primórdios do Curso Normal:

Não tinha livros específicos de psicologia, didática, nada disso. Porque o magistério estava ainda começando, eu fui da segunda turma, então era tudo muito... Não tinha essas coisas modernas como retroprojetor, nada disso. A única coisa que existia era o cartaz de cartolina que o professor fazia, se achasse a figura ele colava e que a gente fazia com figuras de acordo com o assunto da aula, era muito rudimentar.

Em outras palavras, havia poucos recursos didáticos para o ensino. A discente ainda afirma que em todo o tempo em que cursou o Normal não percebeu mudanças, "era aula expositiva, explicava o assunto no quadro de giz. E isso foi até bem mais tarde quando eu já fui fazer o exame de suficiência, que era o concurso" (FARIAS, 2017). 
Percebemos assim, uma dada importância do quadro negro no contexto do ensino da matemática no Curso Normal durante o percurso em estudo. Manoel Jairo Bezerra (1959) aponta como desvantagem do uso do quadro negro, quando esse recurso torna o professor o único ser ativo no processo de ensino e aprendizagem, contudo destaca também que seu uso oferece uma segurança relativa de que o aluno terá acesso ao conhecimento de forma concisa e logicamente organizada com maior rapidez.

Segundo a discente Nina Rosa Braga Cardoso (2017), normalista no período de 1970 a 1972, na disciplina de matemática o conteúdo era explicado pelo professor, usando o quadro que era verde, giz branco e colorido. A citada discente acrescenta que nessa época "usava-se livro e caderno e que dificilmente se trabalhava em grupo na disciplina de matemática, nas outras disciplinas sim, já existiam as equipes formadas com líderes". Desse excerto, importa ressaltar que quase não houve mudanças em termos de utilização de recursos para o ensino, ao compararmos os anos iniciais do curso com os últimos anos de sua vigência.

Jacy Andrade Sturken (2017) conta que:

Quando eu fui aluna, matemática eu só estudei no primeiro ano e estudei como ensinar matemática, como ensinar matemática era realmente... uma aula aos moldes tradicionais mesmo, você jogar a expressão no quadro, o problema no quadro, era quadro, giz e pronto. Não havia essa simulação de ir em um supermercado, em uma venda [...].

Sendo assim, embora as discussões no âmbito da pedagogia no período de 1959 a 1971 tenham demonstrado preocupação para o processo de motivação dos estudantes, conjecturamos, com base nas fontes, que as práticas realizadas no Curso Normal do IERP eram repetitivas e não apresentavam muitas possibilidades para motivar os discentes do citado curso, contudo, segundo afirma Jacy Andrade Sturken (2017), havia orientações para que os normalistas inovassem no momento em que fossem atuar em sala de aula ao informar que:

[...]tinha muitos professores bons que tinha essa abertura, porque não se pode só a matemática com o giz e o quadro de giz, que não era uma lousa não, era o quadro de giz, mas já se dizia: _ Gente leva no supermercado, já tinha essa... já se falava, não se fazia isso no Colégio, mas você podia fazer. Já se tinha essa abertura. [...] você podia levar o aluno no mercadinho e vê que a anotação era feita na caderneta, com a venda a prazo [...]A gente podia levar o aluno, tinha uma livre orientação para trabalhar, não tinha nenhuma repressão dos professores de Didática não [...].

Percebemos então, que havia orientações com relação ao uso de elementos diversos para o ensino de matemática, a fim de que as normalistas não restringissem a prática educativa ao uso do quadro e giz e que associassem o ensino da matemática com aspectos da vida social dos alunos. É importante realçar que, de acordo com os depoimentos coletados nesta pesquisa, as orientações apontadas por Jacy Andrade Sturken (2017), - formada em 1971 - se fez presente na formação de outras normalistas, como por exemplo, Niza Guimarães Pereira (2017), formada em 1965, a qual também destaca que:

No Curso Normal teve uma professora, não lembro a qual, ela sugeriu que a gente usasse esse material com os alunos, mas os alunos teriam 
que comprar para terem esse material, o esquadro, o compasso para fazer círculos, o triângulo, o que até hoje ainda usa.

O depoimento de Niza demonstra que durante sua formação também havia orientações para o uso de recursos diversos no ensino de geometria. Além disso, havia indicações para uso de materiais didáticos no ensino da aritmética, conforme pontua Magnólia Santana de Farias (2017) ao afirmar que a sua turma era orientada a usar:

[...] ábaco, que era um aparelho antigo de contagem, cartazes, a gente preparava os cartazes com o alfabeto, como escrever números, como ler números. Tudo isso na base dos cartazes porque naquela época não tinha o que se tem hoje.

Desse modo, com base nos depoimentos conjecturamos que, embora na prática os docentes do Curso Normal do IERP tenham dado maior importância ao quadro negro, havia orientações para que as normalistas utilizassem outros materiais didáticos no ensino de matemática no primário, no intuito de tornar o ensino mais atraente e relacioná-lo com a vida cotidiana dos alunos.

\section{Considerações finais}

Salientamos que a presente discussão encontra sua relevância ao abordar uma história da formação matemática de professores no primeiro Curso Normal público do município de Jequié, já que até o momento não encontramos pesquisas nesse sentido. A interpretação das fontes, obtidas por esta pesquisa, possibilitaram a construção e disseminação de uma história a respeito da formação matemática dos professores primários formados no citado curso, em um dado período.

As fontes nos levaram a interpretação de que o ensino da matemática no Curso Normal do IERP apresentou uma preponderância do ensino de aritmética com relação ao ensino de geometria. A matemática se fazia presente não apenas na disciplina com esta denominação, mas também na Estatística, no ensino de Desenho e em disciplinas voltadas para o ensino de metodologia.

Os depoimentos revelam que houve, durante algum tempo, uma tensão com relação aos conteúdos a serem adotados na disciplina específica de matemática do currículo do Curso Normal do IERP. Assim, para Niza Guimarães Pereira (2017), os conteúdos adotados eram iguais aos do curso científico, enquanto que para Anísia Rosa Tourinho Simões de Carvalho (2017) o ensino de matemática no Curso Normal adotava os mesmos conteúdos que o ginásio. Entre os motivos que podem ter ocasionado essa tensão podemos citar o fato de que o Curso Normal se estabeleceu como anexo ao Ginásio Estadual de Jequié, vindo assim a adotar a cultura do ginásio e o fato de que tanto o científico como o normal eram cursos secundários; outra questão a ser observada é que o docente de matemática, a princípio, não possuía formação específica para o ensino de matemática no Curso Normal, consequentemente, pode ter pensado que deveria abordar os mesmos conteúdos em ambos os cursos.

Apesar desses indícios, percebemos que, em maior parte do período pesquisado, buscou se relacionar a matemática do Curso Normal ao que se ensinava no curso primário, uma vez que as normalistas deveriam ter propriedade de tais conhecimentos, ou seja, dos 
saberes a ensinar, os quais eram também abordados de forma articulada aos saberes para ensinar. Além dos saberes a ensinar, os professores do Curso Normal do IERP deram destaque aos saberes para ensinar, entre os quais os saberes para ensinar matemática, os quais se destinavam à formação teórica e pedagógica das normalistas e eram abordados, principalmente, nas disciplinas de Metodologia ou Didática e Psicologia. A importância dada à formação teórica e metodológica das normalistas fica perceptível nos depoimentos coletados, em especial das estudantes, percebemos tal relevância também nos livros didáticos e no edital que recrutou docentes auxiliares para o ensino primário de Jequié, em 1959.

\section{Agradecimentos}

Ao Conselho Nacional de Desenvolvimento Científico e Tecnológico (CNPq) pelo financiamento desta pesquisa.

\section{Referências}

ADAMS, Harold P.; DICKEY, Frank G. Princípios básicos de prática de ensino. São Paulo: Editora Fundo de Cultura, 1965.

ARAÚjO, Emerson Pinto de. Carta ao Instituto de Educação Régis Pacheco: a história do IERP, 2012.

ARAÚjO. Emerson Pinto de. Emerson Pinto de Araújo: depoimento [22 mar. 2017]. Entrevistadora: Cleide Selma Pereira dos Santos. Gravação digital (14min e 34s). Depoimento concedido para a pesquisa de Mestrado intitulada "Formação Matemática dos discentes do Curso Normal do IERP: uma investigação histórica".

BAHIA, Lei no 130 de 14 de dezembro de 1948. Dispõe sobre a criação de ginásios oficiais e subvenção de outros existentes no interior do estado. Disponível em: < http://leisestaduais.com.br/ba/lei-ordinaria-n-130-1948-bahia-dispoe-sobre-a-criacao-deginasios-oficiais-e-subvencao-de-outros-existentes-no-interior-do-estado>. Acesso em: 15 set. 2017.

BAHIA, Lei no 737 de 22 de setembro de 1955. Dispõe sobre a instalação de Escolas Normais Oficiais e Escolas Técnico- Profissionais no interior do Estado e dá outras providências. Disponível em: < http://leisestaduais.com.br/ba/lei-ordinaria-n-737-1955bahia-dispoe-sobre-a-instalacao-de-escolas-normais-oficiais-e-escolas-tecnicoprofissionais-no-interior-do-estado-e-da-outras-providencias>. Acesso em: 28 fev. 2018.

BARBOSA, Rui. Reformas do Ensino Primário e várias instituições complementares da instrução pública. Vol.X, Tomo III. Rio de Janeiro: Ministério da Educação e Saúde, 1947.

BERTINI, Luciane de Fátima; MORAIS, Rosilda dos Santos; VALENTE, Wagner Rodrigues. A matemática a ensinar e a matemática para ensinar: novos estudos sobre a formação de professores. São Paulo: Editora Livraria da física, 2017.

BEZERRA, Manoel Jairo. Técnicas de apresentação da matéria e da aprendizagem em matemática. In: MORAES, Ceres Marques de; MELLO e SOUSA, Júlio César; BEZERRA, Jairo Manoel. Apostilas de didática especial de matemática. Rio de Janeiro: CADES, 1959. p. 107. 
BÚRIGO, Elisabete Zardo. Professores modernos para uma nova escola: a formação de professores de matemática nos anos 1960 e 1970. REMATEC, ano 8, n. 13, p. 23-41, mai./ago. 2013.

CARDOSO, Nina Rosa Braga. Nina Rosa Braga Cardoso: depoimento. [30 nov. 2017]. Entrevistadora: Cleide Selma Pereira dos Santos. Jequié, BA, 2016. Gravação digital (15min e 5 s). Depoimento concedido para a pesquisa de Mestrado sobre a formação matemática dos discentes do Curso Normal do IERP.

CARVAlHO, Anísia Rosa Tourinho Simões de. Anísia Rosa Tourinho Simões de Carvalho: depoimento [14 dez. 2016]. Entrevistadora: Cleide Selma Pereira dos Santos. Jequié, BA, 2016. Gravação digital (1 h 23min e 30 s). Depoimento concedido para a pesquisa de Mestrado sobre a formação matemática dos discentes do Curso Normal do IERP.

CHARTIER, Roger. História cultural: entre práticas e representações. Tradução Maria Manoela Galhardo. 2. ed. Lisboa: Difel, 2002.

CHERVEL, André. História das disciplinas escolares: reflexões sobre um campo de pesquisa.

Teoria \& Educação, n. 2, p. 177-229, 1990. Disponível em: <http://moodle.fct.unl.pt/pluginfile.php/122510/mod_resource/content/0/Leituras/Chervel01. pdf>. Acesso em: 08 mai. 2016.

ESTADOS UNIDOS DO BRASIL, Decreto-Lei no 8.530, de 2 de janeiro de 1946. Lei Orgânica do Ensino Normal. Disponível em: < http://www2.camara.leg.br/legin/fed/declei/19401949/decreto-lei-8530-2-janeiro-1946-458443-publicacaooriginal-1-pe.html>. Acesso em: 10 abr. 2017.

ESTADOS UNIDOS DO BRASIL, Portaria no 1045 de 14 de dezembro de 1951. Expede os planos de desenvolvimento dos programas mínimos de ensino secundário e respectivas instruções metodológicas. Disponível em: < https://www.jusbrasil.com.br/diarios/2375333/pg-65-secao-1-diario-oficial-da-uniao-doude-22-02-1952>. Acesso em: 09 nov. 2017.

FARIAS, Magnólia Santana de. Magnólia Santana de Farias: depoimento [15 jun. 2017]. Entrevistadora: Cleide Selma Pereira dos Santos. Gravação digital (58min e 04s). Depoimento concedido para a pesquisa de Mestrado intitulada "Formação Matemática dos discentes do Curso Normal do IERP: uma investigação histórica".

GROSSNICKLE, F. R; BRUECKNER, L. J. O ensino da aritmética pela compreensão. Editora Fundo de Cultura. Brasil - Portugal, 1965.

HOFSTETTER, Rita; SCHNEUWLY Bernard. Saberes: um tema central para as profissões do ensino e da formação. In: HOFSTETTER, Rita; VALENTE, Wagner Rodrigues. Saberes em transformação: tema central da formação de professores. 1. ed. São Paulo: Editora Livraria da Física, 2017a.

HOFSTETTER, Rita; SCHNEUWLY Bernard. Disciplinarização e disciplinação: as ciências da educação e as didáticas das disciplinas sob análise. In: HOFSTETTER, Rita; VALENTE, Wagner Rodrigues. Saberes em transformação: tema central da formação de professores. 1. ed. São Paulo: Editora Livraria da Física, 2017b.

JEQUIÉ. Portaria 60. Jornal oficial do Município de Jequié. ano 1, n. 3, 25 jul. 1959. 
MEIHY, José Carlos sebe Bom. Manual de história oral. 3. ed. São Paulo: Edições Loyola, 1996.

MIRANDA, Dilma Santana. Dilma Santana Miranda. Depoimento [12 dez. 2017]. Entrevistadora: Cleide Selma Pereira dos Santos. Gravação digital (35m e 07s). Depoimento concedido para a pesquisa de Mestrado intitulada "Formação Matemática dos discentes do Curso Normal do IERP: uma investigação histórica".

MOULY, George J. Psicologia Educacional. São Paulo: Gráfica UREPÊS, 1966.

MORAES, Ceres Marques. O material didático; sua importância no ensino da Matemática. In: MORAES, Ceres Marques de; MELLO e SOUSA, Júlio César; BEZERRA, Jairo Manoel. Apostilas de didática especial de matemática. Rio de Janeiro: CADES, 1959.

PEREIRA, Niza Guimarães. Niza Guimarães Pereira: depoimento [04 abr. 2017]. Entrevistadora: Cleide Selma Pereira dos Santos. Gravação digital (1h 50min 37 s). Depoimento concedido para a pesquisa de Mestrado intitulada "Formação Matemática dos discentes do Curso Normal do IERP: uma investigação histórica".

ROSAS, Sílvia Gonçalves Bittencourt Bath. A matemática nos diversos cursos de formação de Professores Primários no Brasil: sua legislação particular, suas peculiaridades locais e seus problemas. In: III CONGRESSO BRASILEIRO DO ENSINO DE MATEMÁTICA, 1959, Rio de Janeiro. Anais... Rio de Janeiro: CADES, 1959, 161-198.

STURKEN, Jacy Andrade. Jacy Andrade Sturken: depoimento [27 mar. 2017]. Entrevistadora: Cleide Selma Pereira dos Santos. Gravação digital (2h 30min 37 s). Depoimento concedido para a pesquisa de Mestrado intitulada "Formação Matemática dos discentes do Curso Normal do IERP: uma investigação histórica".

TANURI, Leonor Maria. História da formação de professores. Revista Brasileira de Educação, Rio de Janeiro: ANPED, n. 14, p. 61-88, mai-ago, 2000.

VALENTE, Wagner Rodrigues. A matemática na formação do professor do primário: São Paulo, 1857-1930. São Paulo: Annablume; Fapesp, 2011.

XAVIER, Odila Barros. Sugestões para Programas em Curso de Aperfeiçoamento de Professôres Primários. In: II CONGRESSO NACIONAL DE ENSINO DA MATEMÁTICA, Rio Grande do Sul, 1957. Anais... 1957, p. 169- 186. 